\title{
Why We Should Tackle Suppressive Gender Stereotypes in the Manosphere
}

\author{
Laura Bates:
}

\section{Men Who Hate Women - From Incels to Pickup Artists, The Truth About Extreme Misogyny and How It Affects Us All}

Simon \& Schuster, London, pages 360, Price: 199,95 DDK at SAXO

\author{
By Lea Skewes \\ Post-Doctoral Researcher, Department of Political Science, Arhus University
}

All feminists hope to change the world for the better. Very few feminists can claim that they have contributed as much to feminist progress as Laura Bates who initiated the famous Everyday Sexism Project. The idea was simple but revolutionary: ask people to report (anonymously online) on their personal experiences with sexism or sexual harassment in their everyday life. This project documented that sexism and sexual harassment is a problem which affects people from all walks of life, in all types of contexts, and all over the world. In other words, it built the foundation for the discussion and the feminist progress that then followed when the \#MeToo movement's international launch started yet another revolutionary anti-sexism campaign in 2017.

Bates' former book "Everyday Sexism" (2014) is a must read for anyone who wants to understand sexism and the suppressive dynamics at play in gender discriminatory interactions. It makes very clear how all-encompassing sexism and sexual harassment is, but also how it is a key element of sexism and sexual harassment that the cards are stacked against the ones who speak out. That is, very often saying "stop", or even labelling the problem as sexism or sexual harassment, leads to very aggressive attempts to silence the people speaking out.

However, backlash experiences have not stopped Bates's battle for justice. In fact, she has managed to turn other people's hate into yet another constructive feminist project by writing a new book called: "Men Who Hate Women - From Incels to Pickup Artists, The Truth About Extreme Misogyny and How It Affects Us All" (2020). This book explores the online platforms of the manosphere. In order to do this, Bates went undercover with a fake online (male) persona, and is now reporting back to us about what she found.

She does not sugar coat their language or their brutal misogyny. On the contrary she reports on it in its horrific detail. The result is brutal reading. Bates systematically unveils one online manosphere platform after the other, laying bare their ideology and offering concrete examples of discussions, as well as the type of material which is 
disseminated amongst the members. Concretely, she goes into detail with four different groups:

- Involuntary Celibate (Incels) and

- Pickup Artists (PUA), whose attitudes to women Bates captures with the following description: "Both groups [incels and Pickup Artists] depend on the separation of men and women into narrow, highly stereotypical categories. Both casts heterosexual sex as the pinnacle of male achievement, and portray women as little more than objects, whose sole purpose is to provide sexual pleasure to men, like some kind of pornographic slot machines. The difference is that incels regard the machine as rigged, paying out only to a few, pre-determined, socially superior elites (...). PUAs, on the other hand, believe it is possible, for a high enough price, to learn the exact secret combination of buttons to push and levers to pull, in order to trick the machine into paying out every time, regardless of the customer" (64).

- Men Going Their Own Way (MGTOW), are men who chose to "eschew relationships with women altogether" (95) because women are considered "irreversibly toxic and dangerous" (96).

- Men's Rights Activists (MRA): who Bates captures as follows: "There is a community of men's organisations focused on tackling issues like mental health, masculine stereotypes and relationship violence. But this isn't it. Instead, MRAs are concerned, to the point of obsession, with attacking women. And their particular target is feminism." (115)

After this introduction to the different representatives of the manosphere (incels, PUAs, MGTOW and MRAs) which you, as a feminist, wish did not exist, and definitely hope never to encounter, Bates reveals how their misogyny and hate is seeping into her own life on an everyday basis in the form of hate mails: "Receiving these messages day in, day out is like drowning in slow motion, but nobody else can see the water. And even if you try and tell them, they don't understand" (144).
Bates goes on to unpack some of the strategies used in order to recruit and gradually radicalise more and more members for the manosphere platforms and ideologies. For instance, she shows how the excuse of irony or satire is intentionally used to gradually desensitise newcommers to increasingly more misogynistic attitudes and actions. She also points to the strategy of using pseudo-scientific facts in order to lend credence to the misogynistic ideologies. Sometimes, even going as far as, inventing fake statistical data, which is then disseminated as scientific "facts".

For a moment, as a reader, you are allowed to hold onto the hope that this extremely misogynistic world might be a unique problem only for outspoken feminists. However, then Bates moves on to reveal how the manosphere discourse, attitudes and actions have already trickled down through the online platforms and into the real-world in the form of real-life politics. She runs through concrete examples of how the pseudo-scientific facts of the manosphere are picked up by politicians all over the world. She offers the example of the most well-known representative from the manosphere, namely Steven Bannon. She shows how Bannon has advised and shaped not only the former American President Donald Trump's policies, but also the current Prime Minister of England Boris Johnson's political speeches (illustrating her point with Johnson's famous speech in which he referred to Muslim women who wear burkas as "letterboxes").

Bates then goes on to show how the manosphere's radicalization process of (particularly young) men is accelerated by platforms such as YouTube, simply because the platform aims to maximise profit. Concretely, YouTube algorithms are developed to increase viewers screen time (because increased screen time equals more exposure to advertisement which is how YouTube makes a profit), and they achieve this by suggesting increasingly radical videos on whatever topic a viewer started out from. This has the consequences that radical misogynistic views are not only sought out by a minority of viewers, but in fact, suggested to viewers who never went looking for these on their own accord. In other words, YouTube's algorithms are designed to offer up 
new recruits for the manosphere and the company benefits financially from this function.

With such powerful financial incentives to offer up more new recruits for the manosphere, and the powerful political players buying into the manosphere discourse, it becomes obvious that this is not just a problem for a few outspoken feminists. It is not just people like Bates, who are "drowning in slow motion" (144) from the exposure to extreme misogyny. The manosphere is a new misogynistic reality we all have to address and tackle, if we want to live in a world where extreme misogyny - and the gender violence that comes along with it - is recognised as the atrocity it in fact is. Toxic gender stereotypes are trickling down from the online manosphere platforms, into our real-world politics, and we need to do something about it if we want to prevent everyone from drowning in toxic gender stereotypes. 